Childhood Sexual Abuse and Attachment Insecurity: Associations with Child Psychological Difficulties

Karin Ensink ${ }^{1}$, Jessica L. Borelli ${ }^{2}$, Lina Normandin ${ }^{1}$, Mary Target ${ }^{3}$ \& Peter Fonagy ${ }^{3}$

1. University of Laval

2. University of California, Irvine

3. University College London

** In press, American Journal of Orthopsychiatry ** 


\begin{abstract}
Although research documents that childhood sexual abuse (CSA) and insecure attachment are associated with psychopathology in children, to date no studies have delineated the unique and interactive contributions of these two risk factors. The aims of this study were to examine attachment in sexually abused children and a comparison group and to assess the contributions of each risk factor to child psychological difficulties. Participants were 111 children aged 7-13, of which 43 were CSA victims. In addition, in the service of enhancing understanding regarding
\end{abstract} CSA, we sought to compare among children experiencing different subtypes of CSA - children whose abusers were members of the family (intrafamilial CSA) versus outside of the family (extrafamilial CSA). We anticipated that intrafamilial CSA would be associated with greater psychopathology risk given that it may involve disruption in children's primary attachment relationships as well as trauma exposure. Children completed an attachment interview and reported on their depressive symptoms. Their mothers reported on children's externalizing symptoms, internalizing symptoms, dissociation, and sexualized behaviour. The findings indicate that, as hypothesized, children with (intrafamilial or extrafamilial) CSA were more likely to be classified as insecure and disorganized. In general, children experiencing intrafamilial CSA showed the most compromised psychological adjustment, followed by children experiencing extrafamilial CSA and then the comparison group. More fine-grained analyses revealed that CSA history was uniquely associated with children's externalizing problems, sexualizing problems, and dissociation, whereas insecure attachment was uniquely associated with child-reported depressive symptoms. Insecure attachment appeared to be protective for internalizing symptoms in the context of CSA, while generally associated with greater risk for psychopathology. Patterns of psychopathology symptoms differed among children exposed to intrafamilial CSA.

Public Policy Relevance: Both childhood sexual abuse and insecure and particularly disorganized attachment are associated with enhanced risk for psychopathology in childhood, 
rendering treatment decision-making difficult for children presenting with multiple sources of risk. The findings of this study suggest that children presenting with sexual abuse histories are more likely to have insecure or disorganized attachment. Further, when children have experienced CSA, particularly CSA that has been perpetrated by a family member, their risk for psychopathology is higher regardless of attachment. Policy makers should prioritize the prevention or treatment of insecure/disorganized attachment among samples of non-abused youth, and the prevention or treatment of trauma-related symptoms among abused children.

Keywords: sexual abuse, child attachment, depressive symptoms, externalizing, dissociation, sexualized behaviors 


\section{Childhood Sexual Abuse and Attachment Insecurity: Associations with}

\section{Children's Psychopathology}

Childhood sexual abuse (CSA) confers risk for mental health difficulties across the lifecycle in $70-75 \%$ of victims (Trickett, Noll, \& Putnam, 2011). Forty-to-sixty percent of children affected by CSA experience psychological problems, including depressive symptoms, externalizing difficulties, sexualized behavior and dissociation (Collin-Vézina, Hébert, \& Brabant, 2007; Ensink, Bégin, Normandin, Godbout, \& Fonagy, 2016; Hébert, Tremblay, Parent, Daigneault, \& Piché, 2006). However, not all children develop mental health difficulties following CSA, and little is known regarding potential protective processes such as attachment (Kwako, Noll Putnam, \& Trickett, 2010). Trickett, Noll and Putnam (2011) argue that CSA activates the child's attachment system and need for comfort and security, suggesting that children whose attachment figures are unreliable in their responsiveness may have more difficulty coping following CSA, and thus be at greater risk for psychopathology. Put concretely, children survivors of CSA with insecure and disorganized attachment relationships may have the highest risk of psychological maladjustment, whereas those with secure attachments may be able to rely upon their relationships to support recovery from this trauma. Further, the impact of CSA on children may depend on the identity of the perpetrator of the abuse, which could be related to children's attachment with primary caregivers and could also interact with children's attachment in predicting children's outcomes. Presently, little is known regarding the relation between CSA and attachment in school-aged children and their association with psychological difficulties; in the current investigation, by exploring psychopathology symptoms in CSA-exposed children and a comparison group, we seek to examine the contributions of children's attachment to the prediction of psychological adjustment, differentiating between CSA perpetrated by persons within and outside of the immediate family. Knowledge regarding the relative contributions of each of these risk factors to children's psychological adjustment is crucial in guiding policy and 
practice.

\section{Attachment}

Attachment theory holds that children develop unconscious schemas of self and others, known as internal working models (IWMs) of attachment, based on the quality of early parent infant interactions. The child's resulting IWM guides thoughts, feelings, and behaviors in close relationships throughout the life cycle (Bowlby, 1980; Bretherton, Ridgeway, \& Cassidy, 1990; George \& Solomon, 1996; Shaver, Collins, \& Clark, 1996). When caregivers consistently provide sensitive care, children develop secure IWMs, conceiving of close relationships as nurturing and of themselves as worthy of love (Bowlby, 1973). These children have the strong sense that they can depend on attachment figures for security when in distress. However, when caregivers consistently or inconsistently reject or ignore their children's bids for attention, children develop an insecure attachment pattern, comprised of the implicit sense that the availability of others is conditional (Bowlby, 1973). Children with insecure-organized attachments adopt either dismissing or preoccupied styles, in which they consistently suppress/deactivate or augment/hyperactivate the expression of their emotional needs, respectively (Cassidy, 1994).

In contrast to organized patterns of attachment, disorganized attachment develops in contexts in which attachment figures behave in frightened, frightening, or role-reversed ways (Hesse \& Main, 2006; Lyons-Ruth, Bronfman, \& Parsons, 1999; Lyons-Ruth \& Jacobvitz, 2008). The resulting disorganization of attachment reflects an absence or collapse of strategy for dealing with attachment-related distress (Hesse \& Main, 2000; Main \& Solomon, 1990), thus increasing risk of psychological difficulties. In middle childhood, researchers can measure children's mental representations of attachment relationships using semi-structured interviews (e.g., the Child Attachment Interview [CAI]; Shmueli-Goetz, Target, Fonagy, \& Datta, 2008); an initial validity study of the CAI revealed that $66 \%$ of children have secure attachment 
representations, $30 \%$ had organized-insecure representations, and $4 \%$ of which were classified as having disorganized attachment (see Privizzini, 2017, for a review).

\section{Attachment, Sexual Abuse and Psychopathology}

Findings from meta-analyses show that both insecure-organized and disorganized children have greater risk for concurrent and later internalizing difficulties (Colonnesi, Draijer, Stams, Van der Bruggen, Bögels, \& Noom, 2011; Groh, Roisman, van IJzendoorn, BakersmansKranenberg, \& Fearon, 2012; Kerns \& Brumariu, 2014; Madigan, Atkinson, Laurin, \& Benoit, 2013), as well as aggressive and externalizing behaviors (Fearon, Bakermans-Kranenburg, van IJzendoorn, Lapsley, \& Roisman, 2010). Disorganized and dismissing attachment may also be an early risk factor for later dissociation (Ogawa, Sroufe, Weinfield, Carlson, \& Egeland, 1997), although all findings are not convergent (Hadigan \& Roisman, 2015) and the link in middle childhood may be indirect (Borelli, David, Crowley, \& Mayes, 2010). In sum, attachment insecurity and disorganization are considered non-specific risk factors that increases the risk for problems in combination with other factors (Kerns \& Brumariu, 2014).

With regard to the simple associations between CSA and attachment, preschool-aged children with CSA are more likely to be classified as having disorganized and preoccupied attachment than non-victims (Fresno, Spencer, Ramos, \& Pierrehumbert, 2014). Furthermore, disorganized attachment is more frequent among adolescents with CSA experiences than in a depressed comparison group and a non-depressed/non-abused comparison group (van Hoof, van Lang, Speekenbrink, van IJzendoorn, \& Vermeiren, 2015).

In addition to the simple associations between CSA exposure and insecure or disorganized attachment with children's psychopathology, there are compelling reasons to believe that these risk factors may interact in the prediction of clinical distress. Sharp, Fonagy, and Allen (2012) developed a theoretical model in which they argue that the social cognition patterns associated with attachment insecurity - perceptions of the self as unlovable and of others 
as unavailable in times of need - predispose people to experience pathological reactions when they experience traumatic events. The key tenets of this theoretical model have been supported in piecemeal in studies of general trauma exposure and post-traumatic stress disorder symptoms in adults and adolescents (e.g., Joubert, Webster, \& Hackett, 2012), and one study found that social cognitive deficits explained the longitudinal association between insecure attachment and posttraumatic stress disorder symptoms in adolescents (Venta, Hatkevitch, Mellick, Vanwoerden, \& Sharp, 2016).

In addition to the historical reasons why youth exposed to CSA may be more likely to experience pathological reactions to the trauma (e.g., internalized mental representations of the self as unlovable/others as unavailable, Sharp et al., 2012), the current interpersonal environments of youth may vary significantly as a function of their attachment relationships with caregivers. The occurrence of CSA is likely to activate children's attachment systems (Trickett et al., 2011), resulting in the child needing more from his/her attachment figures. For instance, if and when the child discloses CSA to caregivers, the parents of a secure child may be more likely to react by validating their child's experiences and increasing their psychological and physical availability to the child. In contrast, parents of insecure children may react by denying the event or minimizing its purported emotional impact on the child; alternatively, they may become overwhelmed or frightened. Both of these types of reactions may decrease the degree to which the parent can serve as an available support for the child, which may impact the degree to which the child can engage in the type of gradual emotional processing that could prevent pathology from developing.

Although these studies provide evidence suggestive that CSA and attachment may have interactive associations with children's adjustment, to date few studies have explored these links in pre-adolescent-aged youth and with respect to CSA in particular. However, the results of a handful of studies of adults suggest that attachment security may protect against the negative 
impact of sexual trauma on psychological adjustment (Aspelmeier, Elliott, \& Smith, 2007) and that attachment insecurity explains the association between sexual trauma and adjustment (Limke, Showers, \& Zeigler-Hill, 2010; Roche, Runtz, \& Hunter, 1999). One study to date examined the associations between attachment insecurity within a sample of preschoolers who had been exposed to CSA, finding that within this population, insecurity conferred risk for internalizing and externalizing difficulties (Zéphyr et al., 2015). To our knowledge, only a single study has tested the contributions of both CSA and attachment to youth's psychological adjustment; Jardin et al. found that among adolescents receiving inpatient psychiatric care, attachment security moderates the association between CSA and trauma symptoms (Jardin, Venta, Newlin, Ibarra, \& Sharp, 2015), such that adolescents with insecure attachment and CSA exposure showed significantly greater trauma symptoms.

\section{Current Investigation}

In an attempt to build on the current knowledge base regarding attachment, CSA, and children's adjustment, we explore a set of research questions within a sample of CSA-exposed school-aged children and a comparison group. We test our hypotheses regarding the interrelations of these constructs during a developmental period during which attachment relationships undergo dramatic shifts, moving from relationships in which physical presence of the caregiver is of the utmost importance to one in which caregivers' central function is one of providing psychological, rather than physical, availability to children. This shift in relational needs is itself an important justification for studying these constructs during middle childhood, but there are additional compelling reasons to focus on this stage. For instance, middle childhood is the developmental phase preceding the onset of increases in psychopathology as well as increases in the importance of romantic relationships and sexual behaviour. Thus, in terms of sensitive periods for the delivery of prevention or intervention efforts, middle childhood may be the most important time in which to understand the links between sexual trauma, attachment, and 
psychological adjustment. Programs effectively targeting children in this phase have the potential to disrupt the link between CSA and sexual victimization in dating relationships (CITE).

The primary aim of this study was to examine the association between attachment and CSA. The second aim was to examine the unique and interactive contributions of attachment and CSA in the prediction of child-reported depressive symptoms, as well as parent-reported externalizing symptoms, sexualized behavior, and dissociation in children. We hypothesized that CSA victims would be more likely to have insecure attachment. Further, we anticipated that CSA and insecure attachment, as well as their interaction, would be associated with increased risk of psychological difficulties.

In all analyses, we first tested the relationship between abuse and attachment measured as constructs with two levels (CSA versus no CSA, secure versus insecure attachment). However, to exploit the richness of the current sample, we also explored associations using three-level variables (no CSA, extrafamilial CSA, and intrafamilial CSA; secure, insecure-organized, disorganized) - although the cell sizes for some of these groups (e.g., disorganized attachment) were small, we reasoned that providing this information may aid investigators in generating hypotheses for subsequent investigations that have more statistical power. Further, to attempt to isolate the unique associations between these two risk factors and children's adjustment, in all analyses, we controlled for potentially confounding indices of psychosocial adversity.

\section{Method}

The protocol for this study was approved by the university ethics board. Parents provided informed consent and children provided informed assent prior to participating in this study; the consent/assent procedures involved informing youth and parents that they could refuse to participate in any portion of the study. Sexually abused children and their mothers were referred to the university clinic by doctors, social services, or mental health practitioners at community health services and hospitals in the city and surrounding regions. The community comparison 
group was recruited through advertisements at Community Health Services and schools through pamphlets soliciting participation in a study on the impact of CSA as part of a comparison group. The comparison group was selected to broadly match the sociodemographic, age (within six months), and gender characteristics of the abused group.

The demographic features of the resulting sample are described in Table 1. More than half $(61.3 \%)$ of the participants were female and the average age of the participants was 9.53 years (SD: 1.45 years), ranging between 7 years and 12 years. Reflecting the socio-demographics of the region, most participants were Caucasian (98\%). Assessments took place at a university child and adolescent consultation service. Parents received a modest stipend to cover transport costs and children were invited to choose a toy or small gift.

\section{Measures}

Children's Abuse History. Information regarding CSA was based on medical and social work reports and information from police inquiries, including statements of admission by the abuser. Parents of comparison group children were interviewed about the child's developmental history and traumatic life events to ensure comparison sample children did not have CSA histories. We classified children into three groupings (no CSA history, extrafamilial CSA history, and intrafamilial CSA history), where intra-familial abuse referred to abuse by members of the immediate family such as a father, father-figure (including the mother's partner), a grandparent, or a sibling.

Child Attachment. The Child Attachment Interview (Shmueli-Goetz et al., 2004) is a semi-structured interview assessing children's attachment representations of their current relationships with their primary caregivers. The interview is similar in format, scope and theoretical underpinnings to that employed in the Adult Attachment Interview (George, Kaplan, \& Main, 1985), but all of these elements of assessing attachment representations are developmentally scaled for measurement in middle childhood (ages 7 to 12). Children are asked 
to describe their relationships with their primary caregivers and to support their descriptions by providing examples of concrete relationship episodes. Trained CAI coders rate the CAI using both verbatim transcripts of CAI narratives and videotapes using ten 9-point scales capturing different aspects of security (e.g., emotional openness, preoccupied anger, idealization, narrative coherence). Based on these scales, coders assign children to one of four attachment categories with respect to each parent: secure, dismissing, preoccupied, and disorganized. In prior studies, most children with two caregivers receive the same classification for both (e.g., Shmueli-Goetz et al., 2008).

The CAI demonstrates concurrent validity in community, clinical, and CSA samples (Borelli et al., 2016a, 2016b; Ensink et al., 2016a; Ensink, Bégin, Normandin \& Fonagy, 2016b; Ensink et al., 2015; Scott, Briskman, Woolgar, Humayun, \& O’Connor, 2011; Scott et al., 2011; Shmueli-Goetz et al., 2008; Target et al., 2003; Venta, Shmueli-Goetz, \& Sharp, 2014), and inter-rater reliability among expert and "naïve" coders is acceptable (e.g., Shmueli-Goetz et al., 2008; see Privizzini, 2017, for a review). In this study, the first author trained two students to code 30 transcripts. The remainder of the transcripts were double coded, and where there was coder disagreement, the first author recoded the transcript and a consensus decision was reached after clarifying and examining reasons for lack of agreement: 4-way classification: Kappa = .91, $p<.001)$.

Children's depressive symptoms. Children completed the Children's Depression Inventory (CDI; Kovacs, 1992), an assessment of depressive symptoms in school-aged children. On this 27-item, psychometrically strong measure (Romano \& Nelson, 1988), children select which of a series of statements describe them best over the past two weeks (e.g., I am sad once in a while, I am sad many times, I am sad all of the time); higher scores signify more severe symptoms. The CDI includes items indexing recent depressive symptoms in behavioral, cognitive, affective, and physiological domains. Internal consistency was good, $\alpha=.86$. 
Children's Behavior Difficulties. The Child Behavior Checklist (CBCL) is a 118-item questionnaire used to assess a broad range of internalizing and externalizing difficulties (Achenbach, 1991). In the present study, we used the parent report internalizing and externalizing scale for children aged 6-18 (Achenbach \& Rescorla, 2001). Parents rate behavior on a three-point scale as 0 (absent), 1 (occurs sometimes), or 2 (occurs often) for items such as, "breaks rules at home, school, or elsewhere". The CBCL has been demonstrated to have good psychometric properties (Achenbach \& Rescorla, 2001). Cronbach’s alphas indicated satisfactory internal consistency in the current study ( $\alpha$ ranged between .87 and .92).

Children's Dissociative Symptoms. The Child Dissociative Checklist (CDC) is a 20item questionnaire developed by Putnam (1990) as a parent-report measure of dissociative symptoms during the past 12 months, created for children aged 5-12. Dissociative symptoms are rated on a 3-point Likert scale; total scores of 12 or above are considered indicative of clinically significant dissociative symptoms. For example, parents are asked to rate items such as "Child goes into a daze or trance-like state at times or often appears "spaced-out" and "Teachers may report that he or she 'daydreams' frequently in school." The CDC demonstrates internal consistency across all studied populations studied (i.e control, sexually abused, dissociative disorder, multiple personality disorder) with Cronbach's alphas ranging from .64 to .91 and .95 for the sample as a whole. It is also considered to have high discriminant validity and good testretest reliability (Putnam, Helmers \& Trickett, 1993).

Children's Sexualized Behavior. The Child Sexualized Behavior Inventory (SBI; Friedrich et al., 2001) is a 35-item parent report behavior checklist assessing sexual behavior in children between two and 12 years old during the previous 6 months. It covers nine domains, including boundary issues, sexual interest, exhibitionism, sexual intrusiveness, gender role behavior, sexual knowledge, self-stimulation, voyeuristic behavior and sexual anxiety. Each item is rated on a 4-point scale from 0 (never) to 4 (at least once a week). The CSBI has been 
demonstrated to have good psychometric properties including item-total correlations and testretest reliability (Friedrich et al., 2001). Total scores are converted to t-scores and t-scores above 65 are considered indicative of clinically significant problems (Friedrich et al., 2001). Cronbach's alphas were satisfactory in the current study, $\alpha=.90$.

\section{Covariates.}

Stressful events. Parents completed the Life Events Record (Coddington, 1972), which asks participants to respond by stating whether a series of negative and positive life events (e.g., death of a close friend, outstanding personal achievement) have occurred in the past year (i.e., by providing a yes/no response). There exists multiple different versions of this questionnaire for assessing stressful life events exposure in different age groups of children; the version developed for elementary aged children contains 35 items and was initially validated among a large sample $(N=887)$. Scoring this measure involves using "life change units," previously assigned to each event by panels of experts, that signify the amount of life change that is required to adjust to the event, which is designed to account for the fact that some events require greater reorganization than others (e.g., beginning another school year $=27$ life change events, versus birth of a baby brother or sister $=50$ life change events). In Coddington's original validity study of this measure, the average number of life events during a year for elementary aged children was 2.63 and the average number of life change units was 102.80 .

Family income. Mothers reported whether their annual household income was below or above 25,000 per year.

\section{Data Analytic Plan}

To examine the association between attachment and CSA history, we conducted Pearson Chi-Square Analyses. To examine both main and interactive effects of the multi-categorical attachment and CSA history variables on children's psychological adjustment, we conducted multivariate analyses of covariance (MANCOVAs) - the use of this analysis enabled us to 
control for confounds and to include all dependent measures in a single analysis, while protecting against multicollinearity. MANCOVAs generate overall $\mathrm{F}$ statistics for the contribution of each independent variable and covariate to the broad set of dependent variables. In addition, we followed these MANCOVAs with Roy-Bargmann step-down analyses, which enabled us to ascertain the specific contributions of each predictor variable to each dependent variable after controlling for the other dependent variable. All analyses were conducted using the two-level abuse variable (no CSA versus CSA) and the two-level attachment variable (secure, insecure). These simpler analyses were followed with analyses involving the three-level abuse variable (no CSA, extrafamilial CSA, intrafamilial CSA) and the three-level attachment variable (secure, insecure-organized, disorganized). Due to the smaller sample size in the three-group CSA and attachment analyses, we encourage researchers to rely most on the two-group analyses. However, we provide the three-group analyses given the paucity of research on this topic and the difficulty of finding these low frequency participants (children with disorganized attachment and children with intrafamilial abuse).

\section{Results}

Descriptive statistics for all key study variables are reported in Table 1. Preliminary analyses indicated that all of the clinical measures were positively intercorrelated. Children's age and gender were not significantly associated with the clinical dependent variables in the study (see Table 1); and thus were not used as covariates in analyses.

Less than half (40\%) of the sample had experienced CSA, of which approximately half had experienced intrafamilial CSA. Of the $20 \%$ who had experienced intrafamilial CSA, $60 \%$ had been abused by their fathers, $18 \%$ by a step-parent, and $22 \%$ by a sibling. Of those who had experienced extrafamilial CSA, some had been abused by a member of the extended family (33\%), while the rest had been abused by an acquaintance (67\%). In addition, approximately $50 \%$ of the children were classified as having secure attachment, $41 \%$ were classified as having 
insecure-organized attachment (21\% classified as dismissing, 20\% preoccupied), and $8 \%$ with disorganized attachment.

Of the sample of CSA-exposed children, 18.2\% experienced CSA on one occasion, $36 \%$ experienced four or more CSA incidents, and the remainder experienced CSA on two or three occasions. About half (54\%) first experienced CSA before 48 months of age. Approximately half (55\%) of the youth denounced the CSA; in the remainder of cases, parents (mother: 19\%, father: $3 \%)$ or other family members $(23 \%)$ denounced the abuse. A minority $(23 \%)$ of the children had vaginal or anal penetration with a penis or object and experienced violent abuse $(5 \%$, but note that it was impossible to determine whether violence occurred for $21 \%$ of the CSA-exposed sample).

Of the children exposed to intrafamilial-CSA, $43 \%$ had CSA perpetrated by the father, $14 \%$ by both parents, $19 \%$ by a sibling, and the remainder by step-parents or acquaintances; $64 \%$ of children exposed to intrafamilial CSA self-denounced the abuse and 50\% were exposed to CSA before 36 months of age.

Analyses of variance (ANOVAs) revealed that family income differed among the different abuse groups, $F(5,109)=3.22, p=.04$, such that children in the non-abused group had parents who reported significantly higher family incomes than children in the intrafamilial CSA group, $p=.02$. Stress exposure was not significantly different among the abuse groups, $F(5,109)$ $=2.66, p=.08$. Further, both family income, $F(5,109)=6.68, p=.002$, and children's stress exposure, $F(5,109)=4.67, p=.01$, differed as a function of children's attachment. With respect to family income, children classified as disorganized had lower family income than children with secure, $p=.001$, and insecure-organized attachment, $p=.02$. With respect to children's sex exposure, secure children reported significantly lower stressful life events than children classified as either insecure-organized, $p=.03$, or disorganized, $p=.01$.

\section{Hypothesis Testing}




\section{Association between childhood sexual abuse and attachment.}

CSA versus no CSA. First we examined whether abuse history (CSA versus no CSA) was associated with children's attachment classifications (secure versus insecure). Results of a Pearson Chi-Square indicated that children's abuse history was significantly associated with their attachment classification, $\chi^{2}(2)=14.27, p=.001$. Children with insecure attachment were more likely to have histories of CSA than secure children.

Next we explored differences in subgroups of insecure attachment, examining secure, insecure-organized, and disorganized attachment separately. Children's abuse history was significantly associated with their attachment classification, $\chi^{2}(2)=14.75, p=.001$. Children with CSA were significantly more likely to be insecure-organized, $p=.001$, and disorganized, $p$ $=.01$, than children without a CSA history.

Understanding differences between extrafamilial and intrafamilial CSA. Next we sought to evaluate links between the subtypes of CSA and children's attachment classifications (Table 2, Figure 1).

A Chi-Square indicated that the 3-level CSA variable (no CSA, extrafamilial CSA, intrafamilial CSA) was significantly associated with children's 2-level attachment classification, $\chi^{2}(2)=14.28, p=.001$. Further, the 3-level CSA variable was also associated with the 3-level attachment variable, $\chi^{2}(2)=16.40, p=.003$. We then aimed to explore children's attachment among children with each subtype of CSA as compared to children without a CSA history.

We first examined whether there were differences in attachment of children who had experienced extrafamilial CSA, compared to children with intrafamilial CSA histories, but no significant differences were found using three way classifications (secure, insecure and disorganized). Compared to non-abused children, children with extrafamilial CSA were significantly more likely to be insecure, $p=.003$, and disorganized, $p=.01$, than secure. 
Compared to non-abused children, children with intrafamilial CSA were also significantly more likely to be insecure, $p=.02$, and disorganized, $p=.01$, than secure.

CSA disclosure as a function of attachment. A Chi-Square indicated that the 2-level attachment classification variable was significantly associated with whether children denounced the abuse, $\chi^{2}(1)=5.96, p=.02$; insecure children were more likely to denounce the CSA themselves (58\% insecure versus 17\% secure). In addition, a Chi-Square indicated that the 3level attachment variable was also significantly associated with children denouncing, $\chi^{2}(2)=$ $7.87, p=.02$, with the pattern of findings suggesting that disorganized children $(83 \%)$ denounced more than insecure-organized (52\%) who denounced more than secure $(17 \%)$.

Of the children exposed to intrafamilial CSA, there was not a significant association between attachment and denouncing of abuse, $\chi^{2}(2)=4.72, p=.09$; all of the disorganized children self-denounced the intrafamilial CSA, whereas $45 \%$ of the insecure-organized children self-denounced and $33 \%$ of secure children did.

Summary of findings. Children who had experienced CSA were more likely to have insecure and disorganized attachment, risk that was highest for children with intrafamilial abuse. Insecure and particularly disorganized children were more likely than secure children to selfdenounce the abuse.

\section{Sexual Abuse History and Attachment in Predicting Children's Psychological}

Symptoms. To address the high intercorrelations of the clinical dependent measures, we conducted MANCOVAs in which all dependent measures were included. In addition, due to the documented associations between overall adversity and risk constructs (CSA and attachment) within our sample, we included as covariates family income and children's exposures to general life stressors.

CSA versus no CSA. First, we conducted a MANCOVA using a two-level abuse variable 
(CSA versus no CSA) and the two-level attachment variable (secure vs. insecure). Controlling for family income, $F(5,109)=1.09, p=.37$, and children's stress exposure $F(5,109)=2.05, p=$ $.08, \mathrm{CSA}, F(1,109)=6.60, p<.001, \dot{n}^{2}=0.26$, and attachment were main effects, $F(2,109)=$ $3.13, p=.01, \dot{\eta}^{2}=0.14$, and the interaction between attachment and abuse, $F(3,109)=3.19, p=$ $.01, \eta^{2}=0.14$, were significant predictors in the model. Follow-up Roy-Bargmann step-down analyses revealed that insecure children had significantly higher CDI scores; abuse history was associated with greater parent-report internalizing and externalizing symptoms, as well as higher dissociation scores. The interaction between the two was uniquely associated with parentreported internalizing symptoms, $p=.01$ (see Figure 2) and externalizing symptoms, $p=.04$.

Next we conducted a MANCOVA using a two-level abuse variable (CSA versus no CSA), controlling for family income, $F(5,109)=0.75, p=.58$, and children's stress exposure $F(5,109)=1.56, p=.17$. CSA was not a significant main effect, $F(1,109)=1.58, p=.17$, but attachment, $F(2,109)=4.50, p<.001, \eta^{2}=0.19$, and the interaction between attachment and abuse, $F(3,109)=3.62, p<.001, \eta^{2}=0.16$, were significant predictors in the model. The main effects revealed that children with CSA and those with disorganized attachment and insecure attachment had higher levels of psychopathology. Obtaining a significant $F$ statistic for the interaction for the overall MANCOVA prompted us to examine which dependent variables were significantly associated with the interaction term using Roy-Bargmann step-down analyses, which included internalizing difficulties, $p=.01$, and dissociation, $p=.002$. The effects in the two different symptom categories were identical -- among children without CSA, disorganized children had significantly higher symptoms than secure or insecure children, $p$ 's $<.05$. However, among children with CSA, no attachment-based differences in symptoms were evident. 
Understanding differences between extrafamilial and intrafamilial CSA. Next, we

conducted a MANCOVA in which we used the three-level abuse variable (no CSA, extrafamilial CSA, intrafamilial CSA). First, we used the two-level attachment variable (secure vs. insecure). Controlling for family income, $F(5,109)=1.03, p=.40$, and children's stress exposure $F(5$, 109) $=2.00, p=.09, \operatorname{CSA}, F(1,109)=3.39, p<.001, \mathfrak{n}^{2}=0.15$, and attachment were main effects, $F(2,109)=3.50, p=.006, \eta^{2}=0.16$, and the interaction between attachment and abuse, $F(3,109)=2.47, p=.008, \eta^{2}=0.12$, were significant predictors in the model. The betweensubjects main effects revealed that insecure children had significantly higher CDI scores; abuse history was associated with greater parent-report internalizing and externalizing symptoms, as well as higher dissociation scores. The interaction between the two was uniquely associated with parent-reported internalizing symptoms, $p=.006$.

Next we conducted the same analysis using the three-level attachment variable (secure, insecure-organized, disorganized). Neither family income, $F(5,109)=0.63, p=.67$, nor children's exposure to stressful life events were significant predictors in the model, $F(5,109)=$ $1.05, p=.39$. Attachment, $F(2,109)=3.40, p<.001, \dot{\eta}^{2}=0.16$, but not CSA, $F(1,109), 1.22$, $p=.28$, was a significant predictor in the model; further, the interaction between the two was a significant predictor in the model, $F(4,109)=2.60, p<.001, \eta^{2}=0.12$. The results of this analysis suggested that sexual abuse history was not associated as a main effect with any of the dependent variables on an individual basis. Disorganized children exhibited significantly more depressive symptoms, $p<.001$, parent-reported externalizing difficulties, $p=.01$, dissociative symptoms, $p=.03$, and sexualized behaviors, $p<.001$. Furthermore, using a Roy-Bargmann step-down analysis we learned that the interaction of attachment and abuse was a statistically 
significant predictor of internalizing difficulties, $p=.02$ (Figure 3A), externalizing difficulties, $p=$ .04 (Figure 3B), and dissociation, $p=.007$ (Figure 4).

With respect to externalizing difficulties, internalizing difficulties and dissociation, the non-abused group and extrafamilial abuse group showed the expected pattern in which disorganized children had more difficulties than other children, $p$ 's $<.05$, whereas in the intrafamilial CSA group, disorganized children's difficulties were not significantly different from insecure and secure children. In contrast, children's self-reported depressive symptoms followed a different pattern - depressive symptoms were only associated with attachment, with children with secure attachments reporting significantly lower symptoms than children with disorganized, $p=.002$, and insecure attachments, $p=.002$, (see Figure 5).

Summary of findings. CSA-exposed children and insecure children exhibited more psychopathology; these two factors interacted such that secure children with CSA exposure had higher psychopathology but disorganized children with CSA had lower psychopathology than disorganized children without CSA. Child-reported depressive symptoms were an exception to this general pattern and were only associated with insecure and disorganized attachment and not CSA history.

\section{Discussion}

The first objective in this study was to examine the association between CSA and attachment in middle childhood. As hypothesized, the findings show that children with CSA were significantly more likely to have insecure and disorganized attachment than children without CSA. This pattern was also found when we compared children with extrafamilial CSA with children without CSA, as well as children with intrafamilial CSA with children without CSA. Importantly, there were no significant differences in attachment between children with intrafamilial CSA and extrafamilial CSA, though in interpreting this finding we must note our sample of intrafamilial abuse was very small. Our findings point to a general pattern wherein 
school-aged children with CSA (whether intrafamilial or extrafamilial) are more likely to also have insecure and disorganized attachment than children without CSA. This extends prior work showing that disorganized attachment is more common in preschool children with CSA (Fresno, Spencer, Ramos, \& Pierrehumbert, 2014), as well as in adolescents with CSA (van Hoof, van Lang, Speekenbrink, van IJzendoorn, \& Vermeiren, 2015).

It is somewhat surprising that the overall frequency of disorganized attachment was so low in the sample. Prior estimates suggest that up to $48 \%$ of maltreated children have disorganized attachment (van IJzendoorn, Schuengel, \& Bakersman-Kranenburg, 1999), but importantly, in the cited study, children experiencing multiple different forms of abuse were included in the sample. In contrast, in this sample, only $14 \%$ of the CSA-exposed children were classified as having disorganized attachment. Previously, researchers have argued that the disorganized attachment classification is in need of additional investigation in terms of how it manifests in middle childhood in general and as measured on the CAI specifically (Borelli et al., 2010; Fearon, Shmueli-Goetz, Viding, Fonagy, \& Plomin, 2014; Privizzini, 2017); for instance, some authors suggest that disorganization may present as dismissing attachment later in development (Fearon et al., 2014; Weinfeld, Whaley \& Egeland, 2004). However, given the limited number of studies on this topic, at this point we cannot conclude whether rates of disorganized attachment are lower among CSA-exposed school-aged children than among children exposed to other forms of abuse, or whether the relatively lower rates of disorganized attachment in this sample pertain to the field's poorer understanding of disorganized attachment in this age range.

The second objective was to examine associations between CSA, attachment and child psychopathology. In this sample CSA, as well as insecure attachment, were associated with higher levels of psychopathology. In general, CSA alone was associated with greater externalizing symptoms, sexualizing problems and dissociation - thus, these symptoms appear to 
be uniquely associated with CSA exposure. The latter two symptom types are known to be sequelae of sexual trauma, whereas that externalizing symptoms were also specifically associated with CSA exposure is more surprising. Further, insecure attachment alone was associated with higher child-reported depressive symptoms, which replicates prior studies documenting such associations in this age range (see Brumariu \& Kerns, 2010; Kerns \& Brumariu, 2014, for reviews). However, parent-reported internalizing symptoms varied as a function of both CSA exposure and attachment, such that among children with CSA, insecure attachment was protective. In general, insecure children showed reduced range of internalizing symptoms across the abuse groups. In contrast, secure children with CSA-exposure were perceived as having significantly greater internalizing symptoms by parents, whereas those without CSA-exposure were perceived as having significantly fewer internalizing symptoms.

Although the findings differed across the clinical outcome examined, they generally revealed a pattern in which the non-CSA/secure children showed the lowest levels of psychopathology while the CSA/secure children showed the highest levels of psychopathology. These findings contradict our initial hypothesis, grounded in theory (Sharp et al., 2012; Trickett et al., 2011) that attachment security would protect against psychopathology in the context of CSA exposure. In interpreting this pattern of effects, we are limited in not knowing the impact of children's disclosure on their clinical outcomes, underscoring the need for this assessment in future investigations. However, we tentatively interpret this in line with the argument that attachment constitutes an adaptive response to the environment - when children experience the caregiving environment as consistently responsive to their needs, they develop the expectation that people will continue to respond to them in a sensitive manner. Perhaps while this set of expectations results in the lowest levels of clinical distress among the non-CSA-exposed youth, the higher levels of distress among secure children exposed to CSA may reveal a lack of preparedness for the type of violation inherent in CSA. In contrast, the insecure children, who 
expect less in terms of others' sensitivity towards them, may experience less disruption from the CSA. This provocative notion remains conjecture until examined in prospective investigations in which the attachment assessment predates the experience of CSA. Explorations of the long-term mental health sequelae of CSA-exposed youth as a function of attachment is also important, as it may be that CSA-exposed/secure children show short-term symptom spikes that attenuate over time, whereas insecure children show longer-term problems.

\section{Exploratory analyses}

In this section, we explore in greater depth the analyses investigating associations between the three-level CSA and attachment categories in the service of informing future research.

Our first point of discussion involves children classified as disorganized, who are generally thought to be at the greatest risk for maladjustment (e.g., van IJzendoorn et al., 1999). In this sample, the rates of disorganized attachment were low but higher than in prior studies of community samples (e.g., Shmueli-Goetz et al., 2008). In the comparison group, disorganized attachment was associated with more psychological difficulties, while in the CSA group there appeared to be no attachment-related differences in symptoms. To further understand these findings and to unpack whether this patterns applied to both the intrafamilial abuse group and the extrafamilial abuse group, we conducted additional analyses among these subgroups. The findings showed that disorganized attachment was generally associated with more psychological difficulties (depressive symptoms, parent-reported externalizing difficulties, dissociative symptoms, and sexualized behaviors). Furthermore, the combination of disorganized attachment and abuse was associated with psychopathology. In the intrafamilial CSA group, there was no attachment-related variation in symptoms. Perhaps in contexts where children experience intrafamilial abuse and its consequent disruption and disorganization, their own attachment disorganization does not make a further significant contribution to psychological difficulties. 
However, in both the non-abused and extrafamilial abuse groups, children with disorganized attachment had more symptoms (externalizing difficulties, internalizing difficulties, dissociation and sexualized behaviors) than other children. This extends previous findings showing that children with disorganized attachments have more difficulties at the level of behavioral regulation (Fearon et al., 2010), likely resulting from the absence of organized strategies for emotion regulation at both physiological and mental representational levels. Dysfunctions in stress regulation may maintain disorganized children in a heightened state of reactivity where affective reactions are behaviorally acted out rather than regulated, because there is not an organized internal process for dealing with distress (Borelli et al., 2010). It is also consistent with previous findings linking dissociation and disorganized attachment (Ogawa et al., 1997) and is in line with Lyons-Ruth's (2015) model suggesting that the contradictory and unintegrated mental processes associated with disorganized attachment render children vulnerable to dissociation.

Next we explore the pattern that emerged with respect to children's self-reported depressive symptoms, which differed in that they were only associated with attachment. Children with secure attachments reporting significantly lower symptoms than children with insecure and disorganized attachment. This finding extends previous findings suggesting that children with insecure and disorganized attachment are at heightened risk for depression (e.g., Borelli, David, Crowley, \& Mayes, 2010). Further, the finding underscores the importance of secure IWMs, which provide children with the sense that they can trust and turn to others when they are distressed. When children do not possess this trust, the intense distress engendered by CSA may escalate into depressive symptoms; in this age range, insecure children are without the psychological resources to be self-reliant yet cannot turn to others, so that they may feel alone and trapped with unbearable feelings and despair.

\section{Implications for Practice and Policy}

Identifying targets of treatment is an important stage in the clinical assessment process, 
particularly among clinicians seeking to treat potential underlying causes of symptoms rather than the symptoms themselves. Our results generally indicate that both insecure attachment and sexual abuse history are associated with enhanced risk for psychopathology in school-aged children; however, insecure attachment is a stronger risk factor among children who have not been sexually abused. When children have experienced CSA, particularly CSA that has been perpetrated by a family member, their risk for psychopathology is higher regardless of attachment. Although correlational, one way in which these findings may inform practice is via the identification of higher order treatment goals - for instance, when working with children with CSA histories, perhaps targeting psychological repercussions of the CSA itself is a more important initial goal than seeking to address general experiences of insecurity within the attachment relationship. Alternatively, among non-abused children, focused on enhancing security in the attachment relationship may constitute an important part of the treatment plan. If these findings are extended to larger samples and using longitudinal designs, they could support an argument for policy-based treatment priorities for children with adverse early life experiences.

\section{Limitations and Future Directions}

The study has a number of strengths, including the use of an interview measure to evaluate attachment and the focus on a difficult-to-recruit but important clinical population. Although the sample was comparable in size to that of other studies of attachment in school-aged children, it was small considering that we were interested in different types of abuse as well as different attachment categories, and thus we lacked power to detect differences, a problem plaguing attachment researchers interested in less common forms of attachment (Cassidy \& Berlin, 1994). In addition, CSA-exposed children are also more likely to experience other forms of psychosocial adversity; to address for this potential confound in the associations examined in this study, we controlled for children's stress exposure, but we acknowledge that this cannot address the potential influence of co-occurring risk factors on children's adjustment. Further, the 
children in this study experienced a range of types and levels of CSA seen in a community sample, but which may be different from the experiences of children put into the care of child protective services, such as severe, chronic CSA together with neglect, physical and emotional abuse. And as stated above, we were not able to examine the role of children's disclosure of CSA or parents' reactions to children's disclosure on outcomes, which is also an area in need of additional investigation. Further research is needed to examine attachment in different samples of children with CSA is thus warranted. In addition, the cross-sectional nature of the study limits the extent to which a temporal developmental sequence can be inferred. 


\section{References}

Achenbach, T. M. (1991). Manual for the Child Behavior Checklist/4-18 and 1991 Profile.

Burlington, VT: University of Vermont, Department of Psychiatry.

Achenbach, T. M., \& Rescorla, L. A. (Eds.), (2001). Manual for the ASEBA school-age forms and profiles. Burlington, VT: University of Vermont, Research Center for Children, Youth, \& Families.

Aspelmeier, J. E., Elliott, A. N., \& Smith, C. H. (2007). Childhood sexual abuse, attachment, and trauma symptoms in college females: The moderating role of attachment. Child Abuse \& Neglect, 31, 549-566. doi:10.1016/j.chiabu. 2006.12.002

Barcons, N., Abrines, N., Brun, C., Sartini, C., Fumadó ,V., \& Marre, D. (2012). Social relationships in children from intercountry adoption. Child Youth Service Review, 34, 955-961. doi:10.1016/j.childyouth.2012.01.028

Barnett, D., Ganiban, J., \& Cicchetti, D. (1999). Maltreatment, negative expressivity, and the development of type D attachments from 12 to 24 months of age. Monographs of the Society for Research in Child Development, 64(3), 97-118. doi:10.1111/15405834.00035

Berthelot, N., Ensink, E., Bernazzani, O., Normandin, L., Luyten, P., \& Fonagy, P. (2015). Intergenerational transmission of attachment in abused and neglected mothers: The role of trauma-specific reflective functioning. Infant Mental Health Journal, 36, 200-212. doi:10.1002/imhj.21499

Borelli, J. L., Crowley, M. J., David, D. H., Sbarra, D. A., Anderson, G. M., \& Mayes, L. C. (2010). Attachment and emotion in school-aged children. Emotion, 10, 475-485. doi: $10.1037 / \mathrm{a} 0018490$

Borelli, J. L., David, D. H., Crowley, M. J., \& Mayes, L. C. (2010). Links between disorganized attachment classification and clinical symptoms in school-aged children. Journal of Child 
and Family Studies, 19, 243-256. doi:10.1007/s10826-009-9292-8

Borelli, J., David, D., Crowley, M., Snavely, J., \& Mayes, L. (2013). Dismissing children's perceptions of their emotional experience and parental care: Preliminary evidence of positive bias. Child Psychiatry and Human Development, 44, 70-88. doi:10.1007/s10578012-0310-5.

Borelli, J. L., Somers, J., West, J. L., Coffey, J. K., De Los Reyes, A., \& Shmueli-Goetz, Y. (2016a). Associations between attachment narratives and self-report measures of attachment in middle childhood: Extending evidence for the validity of the Child Attachment Interview. Journal of Child and Family Studies, 25, 1235-1246. doi:10.1007/s10826-015-0310-8.85

Borelli, J. L., Somers, J., West, J. L., Coffey, J. K., Salim, R., \& Shmueli-Goetz, Y. (2016b). Shedding light on the specificity of school-aged children's attachment narratives. Attachment and Human Development, 18, 188-211. doi:10.1080/14616734.2015.1134605.

Borelli, J.L., West, J.L., Weekes, N. Y., \& Crowley, M. J. (2014). Dismissing child attachment and discordance for subjective and neuroendocrine responses to vulnerability. Developmental Psychobiology, 56, 584-591. doi:10.1002/dev.21107

Bowlby, J. (1973). Attachment and loss: Vol. 2. Separation: Anxiety and anger. New York, NY: Basic Books.

Bowlby, J. (1980). Attachment and loss: Vol. 3. Loss, sadness and depression. New York, NY: Basic Books.

Bretherton, I., Ridgeway, D., \& Cassidy, J. (1990). Assessing internal working models of the attachment relationship. In M. T. Greenberg, D. Cicchetti, \& E. M. Cummings (Eds.), Attachment in the preschool years: Theory, research, and intervention (pp. 273-308). 
Chicago, IL: University of Chicago Press.

Brumariu, L.E., \& Kerns, K.A. (2010). Parent-child attachment and internalizing symptoms in childhood and adolescence: a review of empirical findings and future directions. Development \& Psychopathology, 22, 177-203. doi: 10.1017/S0954579409990344.

Cassidy, J. (1994). Emotion regulation: Influences of attachment relationships. Monographs of the Society for Research in Child Development, 59, 228-249. doi:10.1111/j.15405834.1994.tb01287.x

Cassidy, J., \& Berlin, L. J. (1994). The insecure/ambivalent pattern of attachment: Theory and research. Child development, 65, 971-991. doi:10.2307/1131298

Carlson, V., Cicchetti, D., Barnett, D., \& Braunwald, K. (1989). Disorganized/disoriented attachment relationships in maltreated infants. Developmental Psychology, 25, 525-531. doi:10.1037/0012-1649.25.4.525

Carlson, E. B., Armstrong, J., Loewenstein, R., \& Roth, D. (1998). Relationships between traumatic experiences and symptoms of posttraumatic stress, dissociation, and amnesia. In J. D. Bremner, C. R. Marmar, J. D. Bremner, C. R. Marmar (Eds.), Trauma, memory, and dissociation (pp. 205-227). Arlington, VA: American Psychiatric Association.

Cicchetti, D., Rogosch, F. A., \& Toth, S. L. (2006). Fostering secure attachment in infants in maltreating families through preventive interventions. Development and Psychopathology, 18, 623-649. doi:10.1017/s0954579406060329

Coddington, D.C. (1972). The significance of life events as etiological factors in the diseases of children: II: A study of a normal population. Journal of Psychosomatic Research, 16, 205-213.

Collin-Vézina, D., Daigneault, I., \& Hébert, M. (2013). Lessons learned from child sexual abuse research: Prevalence, outcomes, and preventive strategies. Child and Adolescent Psychiatry and Mental Health, 7, 7-11. doi:10.1186/1753-2000-7-22 
Collin-Vézina, D., Hébert, M., \& Brabant, M.-E. (2007). Agression sexuelle et symptômes de dissociation chez des filles d'âge scolaire. In M. Tardif(Ed.), L'agression sexuelle : coopérer au-delà des frontières, (pp. 347-369). Montréal: Cifas-Institut Philippe Pinel de Montréal.

Colonnesi, C., Draijer, E. M., Jan J. M. Stams, G., Van der Bruggen, C. O., Bögels, S. M., \& Noom, M. J. (2011). The relation between insecure attachment and child anxiety: A meta-analytic review. Journal of Clinical Child and Adolescent Psychology, 40, 630-645. doi:10.1080/15374416.2011.581623

Deblinger, E., Mannarino, A. P., Cohen, J. A., Runyon, M. K., \& Steer, R. A. (2011). Traumafocused cognitive behavioral therapy for children: Impact of the trauma narrative and treatment length. Depression and Anxiety, 28, 67-75. doi:10.1002/da.20744.

DiLillo, D., \& Damashek, A. (2003). Parenting characteristics of women reporting a history of childhood sexual abuse. Child Maltreatment, 8, 319-333. doi:10.1016/S02727358(99)00072-0

Dixon, L., Browne, K., \& Hamilton-Giachritsis, C. (2005). Risk factors of parents abused as children: A mediational analysis of the intergenerational continuity of child maltreatment (Part I). Journal of Child Psychology and Psychiatry, 46, 47-57. doi:10.1111/j.14697610.2004.00339.x

Dwyer, L. (2005). Relevance of triple bottom line reporting to achievement of sustainable tourism: A scoping study. Tourism Review International, 9, 79-93. doi:10.3727/154427205774791726

Ensink, K., Bégin, M., Normandin, L., \& Fonagy, P. (2016a). Maternal and child reflective functioning in the context of child sexual abuse: Pathways to depression and externalising difficulties. European Journal of Psychotraumatology, 7, 1-10. 
doi:10.3402/ejpt.v7.30611

Ensink, K., Bégin, M., Normandin, L., Godbout, N., \& Fonagy, P. (2016b). Mentalization and dissociation in the context of trauma: Implications for child psychopathology. Journal of Trauma and Dissociation, 18, 1-20. doi:10.1080/15299732.2016.1172536

Ensink, K., Berthelot, N., Bernazzani, O., Normandin, L., \& Fonagy, P. (2014). Another step closer to measuring the ghosts in the nursery: Preliminary validation of the Trauma Reflective Functioning Scale. Frontiers in Psychology, 5(1471), 1-12. doi:10.3389/fpsyg.2014.01471_

Ensink, K., Normandin, L., Target, M., Fonagy, P., Sabourin, S., \& Berthelot, N. (2015). Mentalization in children and mothers in the context of trauma: An initial study of the validity of the Child Reflective Functioning Scale. British Journal of Developmental Psychology, 33, 203-217. doi:10.1111/bjdp.12074

Fearon, R. P., Bakermans-Kranenburg, M. J., van IJzendoorn, M. H., Lapsley, A. M., \& Roisman, G. I. (2010). The significance of insecure attachment and disorganization in the development of children's externalizing behavior: A meta-analytic study. Child Development, 81, 435-456. doi:10.1111/j.1467-8624.2009.01405.x

Fearon, R. M. P., Shmueli-Goetz, Y., Viding, E., Fonagy, P., \& Plomin, R. (2014). Genetic and environmental influences on adolescent attachment. Journal of Child Psychology and Psychiatry, 55(9), 1033-1041. doi: 10.1111/jcpp.12171

Fergusson, D. M., Horwood, L. J., \& Lynskey, M. T. (1997).Childhood sexual abuse, adolescent sexual behaviors and sexual revictimization. Child Abuse \& Neglect, 21, 789-803. doi:10.1016/S0145-2134(97)00039-2

Finkelhor, D., Ormrod, R. K., Turner, H. A., \& Hamby, S. L. (2005). Measuring polyvictimization using the Juvenile Victimization Questionnaire. Child Abuse \& Neglect, 29, 1297-1312. doi:10.1016/j.chiabu.2005.06.005 
Fonagy, P., Luyten, P., Campbell, C., \& Allison, L. (2014, December). Epistemic trust, psychopathology and the great psychotherapy debate. Retrieved from http://www.societyforpsychotherapy.org/epistemic-trust-psychopathology-and-the-greatpsychotherapy-debate

Fraley, R. C. (2002). Attachment stability from infancy to adulthood: Meta-analysis and dynamic modeling of developmental mechanisms. Personality and Social Psychology Review, 6, 123-151. doi:10.1207/s15327957pspr0602_03_

Fresno, A., Spencer, R., Ramos, N., \& Pierrehumbert, B. (2014). The effect of sexual abuse on children's attachment representations in Chile. Journal of Child Sexual Abuse, 23, 128145. doi:10.1080/10538712.2014.870949

Friedrich, W. N., Davies, W., Feher, E., \& Wright, J. (2003). Sexual behavior problems in preteen children. Annals of the New York Academy of Sciences, 989, 95-104. doi:10.1111/j.1749-6632.2003.tb07296.x

Friedrich, W. N., Fisher, J. L., Dittner, C. A., Acton, R., Berliner, L., Butler, J., \& ... Wright, J. (2001). Child Sexual Behavior Inventory: Normative, psychiatric, and sexual abuse comparisons. Child Maltreatment, 6, 37-49. doi:10.1177/1077559501006001004

George, C., Kaplan, N., \& Main, M. (1985). The adult attachment interview. Unpublished manuscript, University of California at Berkeley.

George, C., \& Solomon, J. (1996). Representational models of relationships: Links between caregiving and attachment. Infant Mental Health Journal, 17, 198-216. doi:10.1002/(sici)1097-0355(199623)17:3<198::aid-imhj2>3.0.co;2-1

Gloger-Tippelt, G., Gomille, B., Koenig, L., \& Vetter, J. (2002). Attachment representations in 6-year-olds: Related longitudinally to the quality of attachment in infancy and mothers' attachment representations. Attachment \& Human Development, 4, 318-339. doi:10.1080/14616730210167221 
Groh, A. M., Roisman, G. I., van IJzendoorn, M. H., Bakermans-Kranenburg, M. J., \& Fearon, R. (2012). The significance of insecure and disorganized attachment for children's internalizing symptoms: A meta-analytic study. Child development, 83, 591-610. doi:10.1111/j.1467-8624.2011.01711.x

Haltigan, J. D., \& Roisman, G. I. (2015). Infant attachment insecurity and dissociative symptomatology: Findings from the NICHD study of early child care and youth development. Infant Mental Health Journal, 36, 30-41. doi:10.1002/imhj.21479

Hébert, M., Tremblay, C., Parent, N., Daignault, I. V., \& Piché, C. (2006). Correlates of behavioral outcomes in sexually abused children. Journal of Family Violence, 21, 287299. doi:10.1007/s10896-006-9026-2

Hesse, E. \& Main, M. (2000). Disorganized infant, child, and adult attachment: Collapse in behavioral and attentional strategies. Journal of the American Psychoanalytic Association, 48, 1097-1127. doi:10.1177/00030651000480041101

Hesse, E., \& Main, M. (2006). Frightened, threatening, and dissociative parental behavior in low-risk samples: Description, discussion, and interpretations. Development and Psychopathology, 18, 309-343. doi:10.1017/S0954579406060172

Jardin, C., Venta, A., Newlin, E., Ibarra, S., \& Sharp, C. (2015). Secure attachment moderates the relation of sexual trauma sith trauma symptoms among adolescents from an inpatient psychiatric facility. Journal of Interpersonal Violence. 1, 1-21.

doi:10.1177/0886260515589928

Joubert, D., Webster, L., \& Hackett, R. K. (2012). Unresolved attachment status and traumarelated symptomatology in maltreated adolescents: An examination of cognitive mediators. Child Psychiatry and Human Development, 43, 471-483. Doi: $10.1007 / \mathrm{s} 10578-011-0276-8$ 
Kerns, K. A., \& Brumariu, L. E. (2014). Is insecure parent-child attachment a risk factor for the development of anxiety in childhood or adolescence? Child Development Perspectives, 8 , 12-17. doi:10.1111/cdep.12054

Kerns, K. A., Tomich, P. L., Aspelmeier, J. E., \& Contreras, J. M. (2000). Attachment-based assessments of parent-child relationships in middle childhood. Developmental Psychology, 36, 614-626. doi:10.1037/0012-1649.36.5.614

Kisiel, C. L., \& Lyons, J. S. (2001). Dissociation as a mediator of psychopathology among sexually abused children and adolescents. American Journal of Psychiatry, 158, 10341039. doi:10.1176/appi.ajp.158.7.1034

Kovacs, M. (1992). Manual for the children's depression inventory. North Tonawanda, NJ: Multi-Health Systems.

Kriss, A., Steele, H., \& Steele, M. (2012). Measuring attachment and reflective functioning in early adolescence: An introduction to the friends and family interview. Research, Psychotherapy. Psychopathology, Process Outcome, 15, 8795. doi:10.7411/RP.2012.009

Kwako, L. E., Noll, J. G., Putnam, F. W., \& Trickett, P. K. (2010). Childhood sexual abuse and attachment: An intergenerational perspective. Clinical Child Psychology and Psychiatry, 15, 407-422. doi:10.1177/1359104510367590

Limke, A., Showers, C. J., \& Zeigler-Hill, V. (2010). Emotional and sexual maltreat- ment: Anxious attachment mediates psychological adjustment. Journal of Social \& Clinical Psychology, 29, 347-367. doi:10.1521/jscp.2010.29.3.347

Lyons-Ruth, K. (1996). Attachment relationships among children with aggressive behavior problems: The role of disorganized early attachment patterns. Journal of Consulting and Clinical Psychology, 64, 64-73. doi:10.1037/0022-006X.64.1.64

Lyons-Ruth, K., \& Jacobvitz, D. (2008). Attachment disorganization: Genetic factors, parenting 
contexts, and developmental transformation from infancy to adulthood. In J. Cassidy, \& P.R. Shaver (Eds.), Handbook of attachment: Theory, research and clinical applications (pp. 666-697). New York, NY: Guilford Press.

Lyons-Ruth, K., Bronfman, E., \& Parsons, E. (1999). Maternal frightened, frightening, or atypical behavior and disorganized infant attachment patterns. Monographs of the Society for Research in Child Development, 64(3), 67-96. doi:10.1111/1540-5834.00034

Lyons-Ruth, K., \& Spielman, E. (2004). Disorganized infant attachment strategies and helplessfearful profiles of parenting: Integrating attachment research with clinical intervention. Infant mental health journal, 25(4), 318-335. doi:10.1002/imhj.20008

Lyons-Ruth, K. (2015). Dissociation and the parent-infant dialogue: A longitudinal perspective from attachment research. Attachment, 9, 253-276. doi:10.1177/00030651030510031501

Madigan, S., Atkinson, L., Laurin, K., \& Benoit, D. (2013). Attachment and internalizing behavior in early childhood: A meta-analysis. Developmental Psychology, 49, 672-689. doi:10.1037/a0028793

Main, M., \& Solomon, J. (1990). Procedures for identifying infants as disorganized/disoriented during the Ainsworth Strange Situation. In M. T. Greenberg, D. Cicchetti, E. M. Cummings, M. T. Greenberg, D. Cicchetti, E. M. Cummings (Eds.), Attachment in the preschool years: Theory, research, and intervention (pp. 121-160). Chicago, IL: University of Chicago Press.

Maniglio, R. (2012). The role of parent-child bonding, attachment, and interpersonal problems in the development of deviant sexual fantasies in sexual offenders. Trauma, Violence \& Abuse, 13, 83-96. doi:10.1177/1524838012440337

Miljkovitch, R., Pierrehumbert, B., Bretherton, I., \& Halfon, O. (2004). Associations between parental and child attachment representations. Attachment \& Human Development, 6, 
305-325. doi:10.1080/14616730412331281557

Morrel, T. M., Dubowitz, H., Kerr, M. A., \& Black, M. M. (2003). The effect of maternal victimization on children: A cross-informant study. Journal of Family Violence, 18, 2941. doi:10.1023/A:1021401414414

Nelson, E. C., Heath, A. C., Madden, P. A., Cooper, M. L., Dinwiddie, S. H., Bucholz, K. K., ... \& Martin, N. G. (2002). Association between self-reported childhood sexual abuse and adverse psychosocial outcomes: Results from a twin study. Archives of General Psychiatry, 59, 139-145. doi:10.1001/archpsyc.59.2.139

Noll, J. G., Trickett, P. K., \& Putnam, F. W. (2003). A prospective investigation of the impact of childhood sexual abuse on the development of sexuality. Journal of Consulting and Clinical Psychology, 71, 575-586. doi:10.1037/0022-006X.71.3.575

Ogawa, J. R., Sroufe, A., Weinfield, N. S., Carlson, E. A., \& Egeland, B. (1997). Development and the fragmented self : Longitudinal study of dissociative symptomatology in a nonclinical sample. Development and Psychopathology, 9, 855-879. doi:10.1017/S0954579497001478

Paolucci, E. O., Genius, M. L., \& Violato, C. (2001). A meta-analysis of the published research on the effects of child sexual abuse. The Journal of Psychology, 135, 17-36. doi:10.1177/1524838012440337

Polusny, M. A., Rosenthal, M. Z., Aban, I., \& Follette, V. M. (2004). Experiential avoidance as a mediator of the effects of adolescent sexual victimization on negative adult outcomes. Violence and Victims, 19. 109-120. doi:10.1891/vivi.19.1.109.33238

Privizzini, A. (2017). The Child Attachment Interview: A Narrative Review. Frontiers in Psychology, 8, 384. doi: 10.3389/fpsyg.2017.00384

Putnam, F.W. (1990). Disturbances of 'self' in victims of childhood sexual abuse. In R. Kluft (Ed.), Incest-related syndromes of adult psychopathology. (pp. 113-131). Washington, 
DC: American Psychiatric Association.

Putnam, F. W., Helmers, K., \& Trickett, P. K. (1993). Development, reliability, and validity of a child dissociation scale. Child Abuse and Neglect, 17, 731-741. doi:10.1037/e609912012081

Roche, D. N., Runtz, M. G., \& Hunter, M. A. (1999). Adult attachment: A mediator between child sexual abuse and later psychological adjustment. Journal of Interpersonal Violence, 14, 184-207. doi:10.1177/088626099014002006

Romano, B. A., \& Nelson, R. O. (1988). Discriminant and concurrent validity of measures of children's depression. Journal of Clinical Child Psychology, 17, 255-259. doi:10.1207/s15374424jccp1703_10

Rosenthal, M. Z., Hall, M. L. R., Palm, K. M., Batten, S. V., \& Follette, V. M. (2005). Chronic avoidance helps explain the relationship between severity of childhood sexual abuse and psychological distress in adulthood. Journal of Child Sexual Abuse, 14(4), 25-41. doi:10.1300/J070v14n0402

Rumstein-McKean, O., \& Hunsley, J. (2001). Interpersonal and family functioning of female survivors of childhood sexual abuse. Clinical Psychology Review, 21, 471-490. doi:10.1016/S0272-7358(99)00069-0

Scott, S., Briskman, J., Woolgar, M., Humayun, S., \& O'Connor, T. (2011). Attachment in adolescence: Overlap with parenting and unique prediction of behavioral adjustment. Journal of Child Psychology and Psychiatry, 52, 1052-1062. doi:10.1111/j.14697610.2011.02453.x

Shaver, P. R., Collins, N., \& Clark, C. L. (1996). Attachment styles and internal working models of self and relationship partners. In G. J. O. Fletcher, \& J. Fitness (Eds.), Knowledge structures in close relationships: A social psychological approach (pp. 25-61). Hillsdale, NJ: Erlbaum. 
Shapiro, D. L., \& Levendosky, A. A. (1999). Adolescent survivors of childhood sexual abuse: The mediating role of attachment style and coping in psychological and interpersonal functioning. Child Abuse \& Neglect, 23, 1175-1191. doi:10.1016/s0145-2134(99)00085$\mathrm{X}$

Shmueli-Goetz, Y. (2014). The Child Attachment Interview (CAI). In S. Farnfield, \& P. Holmes, (Eds.), The routledge handbook of attachment: Assessment (pp. 119-133). London \& New York: Routledge.

Shmueli-Goetz, Y., Target, M., Datta, A., \& Fonagy, P. (2004). Child Attachment Interview (CAI) coding and classification manual, version $V$. Unpublished manuscript, The SubDepartment of Clinical Health Psychology, University College London.

Shmueli-Goetz, Y., Target, M., Fonagy, P., \& Datta, A. (2008). The Child Attachment Interview: A psychometric study of reliability and discriminant validity. Developmental Psychology, 44, 939-956. doi:10.1037/0012-1649.44.4.939

Steele, H., \& Steele, M. (2005). The construct of coherence as an indicator of attachment security in middle childhood: The Friends and Family Interview. In K. Kerns \& R. Richardson (Eds.), Attachment in middle childhood (pp. 137-160). New York, NY: Guilford Press.

Target, M., Fonagy, F., \& Shmueli-Goetz, Y. (2003). Attachment representation in school-age children: The development of the child attachment interview (CAI). Journal of Child Psychotherapy, 29, 171-186. doi:10.1080/0075417031000138433

Thompson, R. A., \& Raikes, H. A. (2003). Toward the next quarter century: Conceptual and methodological changes for attachment theory. Developmental Psychopathology, 15, 691-718. doi:10.1017.S0954579403000348

Trask, E. V., Walsh, K., \& DiLillo, D. (2011). Treatment effects for common outcomes of child sexual abuse: A current meta-analysis. Aggression and Violent Behavior, 16, 6-19. 
doi:10.1016/j.avb.2010.10.001

Trickett, P. K., Noll, J. G., \& Putnam, F. W. (2011). The impact of sexual abuse on female development: Lessons from a multigenerational, longitudinal research study. Development and Psychopathology, 23, 453-476. doi: $10.1017 / \mathrm{S} 0954579411000174$

van IJzendoorn, M. (1995). Adult attachment representations, parental responsiveness, and infant attachment: A meta-analysis on the predictive validity of the Adult Attachment Interview. Psychological bulletin, 117, 387-403. doi:10.1037/0033-2909.117.3.387

van IJzendoorn, M., Schuengel, C, \& Bakersmans-Kranenburg, M.J. (1999). Disorganized attachment in early childhood: meta-analysis of precursors, concomitants, and sequelae. Development \& Psychopathology, 11, 225-49. doi: 10.1017/ S0954579499002035. van Hoof, M. J., van Lang, N. D., Speekenbrink, S., van IJzendoorn, M. H., \& Vermeiren, R. R. (2015). Adult Attachment Interview differentiates adolescents with childhood sexual abuse from those with clinical depression and non-clinical controls. Attachment \& Human Development, 17, 354-375. doi:10.1080/14616734.2015.1050420

van Roode, T., Dickson, N., Herbison, P., \& Paul, C. (2009). Child sexual abuse and persistence of risky sexual behaviors and negative sexual outcomes over adulthood: Findings from a birth cohort. Child Abuse \& Neglect, 33, 161-172. doi:10.1016/j.chiabu.2008.09.006 Venta, A., Hatkevitch, C., Mellick, W., Vanwoerden, S., \& Sharp, C. (2017). Social cognition mediates the relation between attachment schemas and posttraumatic stress disorder. Psychological Trauma: Theory, Research, Practice, and Policy, 9, 88-95. doi: $10.1037 / \operatorname{tra} 0000165$

Venta, A., Shmueli-Goetz, Y., \& Sharp, C. (2014). Assessing attachment in adolescence: A psychometric study of the Child Attachment Interview. Psychological Assessment, 26, 238-255. doi:10.1037/a0034712 
Weinfield, N.S., Whaley, G.J.L., \& Egeland, B. (2004). Continuity, discontinuity, and coherence in attachment from infancy to late adolescence: Sequelae of organization and disorganization. Attachment \& Human Development, 6, 73-97.

White, L., O, Wu, J., Borelli, J. L., Mayes, L. C., \& Crowley, M.C. (2013). Play it again: Neural responses to reunion with excluders predicted by attachment patterns. Developmental Science, 16, 850-863. doi:10.1111/desc. 12035

Zéphyr, L., Cyr, C., Hébert, M., Bernier, A., \& Beaudoin, G. (2015). Problèmes de comportement chez l'enfant victime d'agression sexuelle: Le rôle de l'attachement. Canadian Journal of Behavioral Science/Revue Canadienne des Sciences $d u$ Comportement, 47, 91-101. doi:10.1037/a0037 